\title{
A case-control study of chronic neuropsychiatric disease and organic solvent exposure in automobile assembly plant workers
}

\author{
Nancy A Nelson, Thomas G Robins, Roberta F White, Richard P Garrison
}

\begin{abstract}
A case-control study of chronic neurological and psychiatric disease and occupational exposure to solvents was carried out in eight automobile assembly plants. Cases included 299 subjects who were granted medical disability retirement in 1980-8. Two control groups were selected, the first from those granted retirement in the same period because of medical disability from causes unrelated to solvent exposure. The second included hourly employees from the plant population. In these facilities, solvent exposures tended to be short term and low level, although common: the average duration of exposure was 2.3 years; about $41 \%$ experienced at least one day of exposure. Of those exposed, $46 \%$ had less than one year of exposure. Results for all psychiatric disease combined (273 cases) suggested that cases had lower exposures than either control group, regardless of how exposure was expressed. Results could not be explained by conventional confounding exposures or characteristics or by usual manifestations of the healthy worker effect. By contrast, chronic neurological disease, and multiple sclerosis in particular, seemed to be associated with exposure, although few cases were identified and observed increases in risk were not statistically significant.
\end{abstract}

(Occup Environ Med 1994;51:302-307)

Assessment and
Research for
Prevention,
Department of Labor
and Industries, State
of Washington,
Olympia, WA, USA
N A Nelson
Department of
Environmental and
Industrial Health,
University of Michigan
School of Public
Health, Ann Arbor,
MI, USA
T G Robins
R P Garrison
Department of
Neurology, Boston
University School of
Medicine, Boston VA
Medical Center,
Boston, MA, USA
R F White
Requests for reprints to:
Nancy Nelson, SHARP,
Department of Labor and
Industries, State of
Washington, PO Box 44330,
Olympia, WA 98504-4330,
USA.
Accepted 23 November 1993

Safety and Health

Prevention,

Department of Labor

and Industries, State

of Washington,

N A Nelson

Department of

Environmental and

University of Michigan

School of Public

Health, Ann Arbor,

Department of

Neurology, Boston

University School of

Medicine, Boston VA

R F White

Requests for reprints to Nancy Nelson, SHARP, Department of Labor an Washington, PO Box 44330 USA.

Accepted 23 November 1993

Exposure to organic solvents has been related to many changes in function of the human nervous system, as measured by reports of symptoms, psychometric and neurobehavioural testing, and occurrence of overt neurological and psychiatric disease. In Scandinavian countries, where many cases have been reported, solvent induced psychoorganic syndrome is a recognised compensatable disorder.

Results from most previous epidemiological studies of chronic disease and exposure to mixed solvents cannot be directly related to United States populations, as many investigations were carried out in European countries where exposures and case definitions differed. Case-control studies of chronic neuropsychiatric disability in particular are rather specific to the industrial policies and work practices in place where the study is carried out, and results may be affected by selection factors. In this investigation, a case-control approach was used to examine the relations between chronic neuropsychiatric disease and solvent exposure in a group of United States automobile assembly plants, to quantify risk in this environment, and to compare them with those found in other studies. This study used more detailed methods of exposure assessment to better quantify relations.

\section{Methods}

STUDY GROUP

The study group included 1243 cases and controls who worked at any of eight automobile assembly plants located in Michigan and Ohio. Cases included all those taking a medical disability retirement because of psychiatric or neurological disease in the 1980-8 period. Eligibility for this type of retirement required that employees had worked for the company for 10 or more years. Charts for cases with neurological and psychiatric disorders were reviewed by a clinical neuropsychologist; diagnoses were coded from the ninth revision of the International Classification of Diseases. ${ }^{1}$ Targeted diagnoses fell into five neurological categories (toxic encephalopathies, parkinsonism, multiple sclerosis, cerebellar and spinocerebellar diseases, and organic neuropsychiatric diseases) and five psychiatric categories (selected psychoses, affective disorders, personality disorders, anxiety disorders, and chemical dependencies) (diagnosis codes available on request).

Two control groups were selected: "disabil- ity" controls were chosen from a file of employees who took disability retirement for disorders other than those of interest. Employees with leukaemia and secondary renal, psychiatric, and neurological diseases were excluded from consideration. "Population" controls were selected from hourly 1980-8 period with at least 10 years of employment. Controls were individually matched to cases on plant where worked, sex, race, birth date, hire date and employment duration (the last three to within three years). All controls meeting the matching criteria for whom complete medical and employment history records were available were included in analyses.

\section{CONFOUNDERS}

Factors that may confound the relation between exposure to solvents and the outemployees who worked at some time in the 
comes of interest include both other occupational exposures, considered in a later section on exposure assessment, and selected medical conditions. Alcoholism (present or absent) was included in analyses as a potential confounder.

SOLVENT EXPOSURE

Automobile plants with potential for high solvent exposures include those that assemble automobiles, lorries, engines, radiators, and fuel injectors. These processes involve degreasing and wiping of metal parts, spray painting and spray booth cleaning, adhesive and sealer application, and use of solvents in testing products. The major classes of organic solvents used currently and historically include alcohols, aromatics, acetates and esters, halogenated hydrocarbons, ethers, glycols, ketones, and petroleum distillates.

\section{EXPOSURE ASSESSMENT}

A detailed description of exposure assessment methodology used appears elsewhere. ${ }^{2}$ Briefly, information on work history of study members was taken from personnel records that listed department and job assignments and dates when worked. Records were abstracted and entered into a computer to produce a list showing all job assignments for the entire study group. Industrial hygiene records maintained by the company were used to create a data base of solvent and lead air sampling results for targeted plants (a total of 6009 samples). Two industrial hygienists knowledgeable about exposures in this industry used these data, along with information regarding current and historical exposures obtained by observation of current operations and interview of plant personnel, to assign semiquantitative exposure indices to the list of job assignments. Individual jobs were designated as unexposed to solvents or having low or high exposure (estimated as having less or greater than $50 \%$ of the 1990 threshold limit value for solvent mixtures). Potential for exposure to halogenated, non-halogenated, or both types of solvents was also designated, as well as whether the job had potential for dermal exposure. For each study member, exposure was expressed as total years working with exposure to halogenated, non-halogenated, and all solvents and years working in selected solvent exposed tasks.

Table 1 Automobile assembly plant workers and neuropsychiatric disease: demographic description of study cases and eligible population ${ }^{\star}$

\begin{tabular}{|c|c|c|c|}
\hline & \multicolumn{3}{|c|}{ Diagnostic group } \\
\hline & Neurological & Psychiatric & Eligible† \\
\hline $\mathbf{n}$ & 109 & 256 & 60287 \\
\hline White males (\%) & 67.9 & $55 \cdot 9$ & $72 \cdot 6$ \\
\hline Black males (\%) & $18 \cdot 4$ & $23 \cdot 8$ & $12 \cdot 5$ \\
\hline White females (\%) & $7 \cdot 3$ & $9 \cdot 8$ & $8 \cdot 3$ \\
\hline Black females (\%) & $6 \cdot 4$ & $10 \cdot 6$ & 3.9 \\
\hline Birth year (mean) & 1936 & 1940 & 1941 \\
\hline Hire year (mean) & 1965 & 1967 & 1966 \\
\hline Years of employment (mean) & $20 \cdot 7$ & $18 \cdot 4$ & $21 \cdot 0$ \\
\hline Age at hire (mean) & $29 \cdot 0$ & $26 \cdot 6$ & $24 \cdot 9$ \\
\hline Years of education (mean) $\dagger$ & $10 \cdot 3$ & $10 \cdot 9$ & Not available \\
\hline$\%$ Married (mean) $\dagger$ & $62 \cdot 7$ & $54 \cdot 2$ & Not available \\
\hline
\end{tabular}

*Eligible population includes those with 10 or more years seniority who were actively employed in 1980 or later. tAt time of hire.
Work histories were also evaluated to determine whether each job assignment involved potential confounding occupational exposure to lead (coded as yes or no).

Information on work history for periods before hire by the company was obtained from employment applications, which listed previous jobs and dates when held. Exposure to neurotoxicants (solvents, selected heavy metals, and pesticides) was determined by comparing job descriptions with lists of occupations with known exposure described in a standard guide to occupational disease. ${ }^{3}$ Exposure was classified as present or absent.

\section{STATISTICAL METHODS}

Cumulative exposures were calculated from the first day a subject worked until selected cut off dates: (a) date when matched controls attained the age when the case became a case (estimated date of disease onset); $(b)$ date when controls attained the age when the case was granted a disability retirement; (c) date five years after hire; $(d)$ date when first job ended; and $(e) 10$ years after onset of disease. In all instances, measures were calculated with actual time worked (absences of one month or more were subtracted from cumulated years worked).

Univariate and multivariate analyses were carried out with conditional logistic regression. A nested model approach was used to determine effects of potential confounders, solvent exposures, and interactions between exposure and other variables. Final models were selected based on how well they described relations and statistical significance (by log likelihood testing).

\section{Results}

Most of the eight plants included in the study began production in the early 1900 s; five are currently still in operation and three closed in the late 1980s. Hourly populations as of 1985 ranged from about 4000 to 15000 . All but one plant were primarily automobile, van, and lorry assembly plants; as well as assembly, the dissimilar plant included gear and axle, engine assembly, plating, press metal, chassis, and foundry operations.

The study group included a greater proportion of women and black workers than the underlying population (workers with 10 or more years of employment; table 1). On average, cases were slightly older, were employed for fewer years, and were older at hire than the eligible population. The average hire date was in the mid-1960s

Cases were typically given more than one diagnosis, as available medical documentation often seemed consistent with more than one illness. Only 72 of 299 neurological and psychiatric cases had a single diagnosis assigned (with ranges of one to four and one to seven diagnoses for each group respectively). Average age at onset was about 36; the average time between hire and disease onset was $9 \cdot 5$ years.

The group of disability controls largely 
comprised those with cardiovascular and musculoskeletal disorders: $32 \cdot 7,27 \cdot 2,15 \cdot 2$, $6 \cdot 1$, and $5 \cdot 7$ had diagnoses for cardiovascular diseases, musculoskeletal disorders, neoplasms, non-malignant respiratory disease, and accidents respectively. Matching ratios varied considerably within each control group; average case:control ratios were 1:1.2 and 1:1.9 for disability and population controls respectively.

EXPOSURE TO NEUROTOXICANTS BEFORE HIRE Employment applications listing job histories for the period before hire by the automobile company were available for $91.9 \%$ of the study group. Few seemed to have held jobs with exposure to heavy metals: none was exposed to mercury, and only four held jobs involving exposure to lead. Five per cent held previous positions with potential pesticide exposure, and $12 \cdot 7 \%$ held positions working with solvents $(61 \%$ of which were low exposure jobs). The mean duration for previous solvent exposure was about two years (for those with such exposure).

\section{EXPOSURE TO LEAD AND SOLVENTS IN} AUTOMOBILE ASSEMBLY PLANTS

Most study participants were hired by the automobile company in 1960 or later, with hire dates ranging from 1942 to 1978 . The mean duration of employment was 15.9 years for the entire cohort; the average number of years working with solvents was 2.3 (about $15 \%$ of employment duration). The most common solvent exposed jobs included selected skilled trades positions, spray painting, hand degreasing, application of adhesives and sealers, and paint booth cleaning. The distribution of exposure was highly skewed, with $59 \%$ of study participants experiencing none. Of those exposed, $46 \%$ had less than one year of exposure. Mean exposures to nonhalogenated and halogenated solvents were similar at 1.9 and 1.7 years respectively. Some tasks were classified as having simultaneous halogenated and non-halogenated exposure; the correlation between the two measures was high (Spearman correlation coefficient 0.71). Low level exposure was more common than high, with 1.9 and 0.4 mean years of exposure respectively for the entire study group.

Lead exposures for the group were low (an average of 0.9 years), and in general were not correlated with solvent exposure (Spearman correlation coefficient 0.33 ). Simultaneous exposure to lead and solvents was common, however, in spray paint areas $(r=0.61)$, as in the past, automobile and truck paints contained lead pigments.

\section{ANALYTICAL RESULTS}

Analyses were carried out individually for all 10 diagnostic categories. Results for only three diagnostic groups are presented: multiple sclerosis, combined neurological disease (excluding multiple sclerosis and organic neuropsychiatric disease), and for all diagnoses of psychiatric disease combined. The reasoning for grouping is because most psychiatric cases had multiple psychiatric diagnoses and came in more than one diagnostic category, so results were similar for these groups. The number of neurological cases were small, suggesting they should be grouped together; however, results for the multiple sclerosis group differed and are thus presented separately.

\section{PSYCHIATRIC DISEASE}

For most expressions of exposure, measures for cases were lowest, measures for disability controls were intermediate, and measures for population controls were highest (average exposure durations of $1.4,1 \cdot 7$, and $3 \cdot 1$ years respectively). Because many of the task related exposure variables were highly correlated with years of total solvent exposure, further analyses focused on two expressions: total years exposed to solvents and years with high level exposure (any type). Because of the many study participants with no exposure and the non-normal distribution of data, exposures were expressed categorically in analyses.

Analysis by univariate conditional logistic regression produced odds ratios (ORs) less than unity for both control groups when exposure was defined dichotomously in several ways. For example, with a five year dichotomy, ORs were 0.69 (95\% confidence interval $(95 \% \mathrm{CI}) 0.36-1.31)$ and $0.32(95 \%$ CI $0.18-0.54)$ for the higher exposure category for disability and population controls respectively. Results examining effects of high level exposure were similar.

Univariate regressions examining effects of potential confounding exposures-lead in the automobile plant workplace and preautomobile plant exposure to lead, mercury, pesticides, or solvents-indicated that these were not related to outcome diagnoses, with ORs of about one. Univariate effects of alcohol consumption were examined for cases and the disability control group only, although many study participants had missing data and information bias was strongly suspected. When consumption was expressed as heavy drinker or alcoholic $v$ not, the OR was $3 \cdot 1$ (95\% CI $1 \cdot 61-6 \cdot 14)$.

Additional analyses were conducted in an attempt to explain the apparent protective effect of exposure. Results were examined excluding outliers with extremely long solvent exposures (20 or more years), using various methods for calculating cumulative exposure (truncating exposure at the end of the first job held and at five and 10 years of employment, truncating at the date of case's disease onset and at the time of disability retirement award, by including only exposures occurring 10 or fewer years before the date of disease onset), excluding cases (and their controls) diagnosed with alcoholism or schizophrenia, carrying out separate analyses for each diagnostic group, excluding those whose diseases clearly preceded hire, examining race and sex groups separately, examining results separately for each plant, and adding a potentially confounding variable indicating whether study participants held skilled trades positions for half or more of their employment duration. 
All these analyses produced similar resultsthat is, cases tended to have lower exposure than controls (population controls in particular).

Tables 2 and 3 show coefficients for the final models for both control groups: the trend for decreasing risk of disease with increasing exposure was less apparent for disability controls. For population controls, those working in skilled trades jobs had lower overall risks, although the same inverse relation between exposure and outcome was found.

\section{NEUROLOGICAL DISEASE}

Eighteen cases of neurological disease (excluding multiple sclerosis) were identified.

Table 2 Relation between psychiatric disease and solvent exposure in automobile workers: conditional logistic regression coefficients and ORs for model expressing exposure categorically; disability control group

\begin{tabular}{|c|c|c|c|c|c|}
\hline $\begin{array}{l}\text { Time } \\
\text { Exposed }\end{array}$ & Coefficient & SEM & p Value & $O R$ & $(95 \% C I)$ \\
\hline $\begin{array}{l}0 \\
\text { To } 2 \text { months } \\
2 \text { months- } 3 \text { years } \\
\geqslant 3 \text { years }\end{array}$ & $\begin{array}{l}0.047 \\
0.069 \\
-0.14\end{array}$ & $\begin{array}{l}0.38 \\
0 \cdot 28 \\
0 \cdot 29\end{array}$ & $\begin{array}{l}0.22 \\
0.81 \\
0.62\end{array}$ & $\begin{array}{l}1.0 \\
1.60 \\
1.07 \\
0.87\end{array}$ & $\begin{array}{l}(0.75-3.41) \\
(0.61-1.87) \\
(0.49-1.53)\end{array}$ \\
\hline
\end{tabular}

p Value for model 0.57 .

Table 3 Relation between psychiatric disease and solvent exposure in automobile workers: conditional logistic regression coefficients and ORs for model expressing exposure categorically; population control group

Population controls (273 cases, 530 controls)

\begin{tabular}{|c|c|c|c|c|c|c|c|}
\hline \multirow{2}{*}{$\begin{array}{l}\text { Time } \\
\text { Exposed }\end{array}$} & \multirow[b]{2}{*}{ Coefficient } & \multirow[b]{2}{*}{$S E M$} & \multirow[b]{2}{*}{$p$ Value } & \multicolumn{2}{|c|}{ Non-skilled } & \multicolumn{2}{|c|}{ Skilled } \\
\hline & & & & $O R$ & $(95 \% C I)$ & $O R$ & $(95 \% C I)$ \\
\hline $\begin{array}{l}0 \\
\text { To } 2 \text { months } \\
2 \text { months }-3 \text { years } \\
\geqslant 3 \text { years }\end{array}$ & $\begin{array}{r}0.65 \\
0.11 \\
-0.60\end{array}$ & $\begin{array}{l}0.31 \\
0 \cdot 24 \\
0 \cdot 26\end{array}$ & $\begin{array}{l}0.037 \\
0.64 \\
0.024\end{array}$ & $\begin{array}{l}1.0 \\
1.91 \\
1.12 \\
0.55\end{array}$ & $\begin{array}{l}(1.05-3.5) \\
(0.70-1.80) \\
(0.32-0.92)\end{array}$ & $\begin{array}{l}1.0 \\
0.99 \\
0.58 \\
0.29\end{array}$ & $\begin{array}{l}(0.65-1.50) \\
(0.41-0.82) \\
(0.22-0.37)\end{array}$ \\
\hline
\end{tabular}

p Value for model 0.0001 .

Table 4 Relation between neurological disease and solvent exposure in automobile workers: univariate conditional regression ORs for selected exposure variables and potential confounders. Neurological disease excluding multiple sclerosis (18 cases)

\begin{tabular}{|c|c|c|c|c|}
\hline \multirow[b]{2}{*}{ Variable } & \multicolumn{2}{|c|}{ Disability controls } & \multicolumn{2}{|c|}{ Population controls } \\
\hline & $O R$ & $(95 \% C I)$ & $O R$ & $(95 \% C I)$ \\
\hline $\begin{array}{l}\text { Ever/never exposed } \\
\pm 1 \text { year } \\
\pm 1 \text { year, high level } \\
\text { Lead } \\
\text { Alcohol }\end{array}$ & $\begin{array}{l}1 \cdot 8 \\
2 \cdot 0 \\
1 \cdot 4 \\
5 \cdot 9 \\
7 \cdot 2\end{array}$ & $\begin{array}{l}(0.5-6.7) \\
(0.5-7 \cdot 8) \\
(0.2-9.5) \\
(0.6-60.5) \\
(0.8-63.8)\end{array}$ & $\begin{array}{l}0 \cdot 71 \\
0 \cdot 40 \\
0 \cdot 66 \\
2 \cdot 20\end{array}$ & $\begin{array}{l}(0 \cdot 2-2 \cdot 3) \\
(0 \cdot 1-1 \cdot 6) \\
(0 \cdot 2-2 \cdot 7) \\
(0 \cdot 5-9 \cdot 7)\end{array}$ \\
\hline
\end{tabular}

*Ever/never $=$ any solvent exposure $v$ none; \pm 1 year $=$ more or less than one year of solven exposure; \pm 1 year, high-level = more or less than one year of high solvent exposure; lead = more or less than 0.5 years of exposure to lead; alcohol $=$ alcoholic $v$ not.

Table 5 Relation between multiple sclerosis and solvent exposure in automobile workers: univariate conditional regression ORs for selected exposure variables and potential confounders. Multiple sclerosis (20 cases)

\begin{tabular}{|c|c|c|c|c|}
\hline \multirow[b]{2}{*}{ Variable } & \multicolumn{2}{|c|}{ Disability controls } & \multicolumn{2}{|c|}{ Population controls } \\
\hline & $O R$ & $(95 \% C I)$ & $O R$ & $(95 \% C I)$ \\
\hline $\begin{array}{l}\text { Ever/never exposed } \dagger \\
\pm 1 \text { year } \\
\pm 1 \text { year, high level } \\
\text { Lead } \\
\text { Alcohol }\end{array}$ & $\begin{array}{l}2 \cdot 0 \\
2 \cdot 7 \\
\text { NP } \\
8 \cdot 2 \\
\text { NP }\end{array}$ & $\begin{array}{l}(0 \cdot 6-6 \cdot 9) \\
(0 \cdot 6-13 \cdot 0) \\
(0 \cdot 7-95 \cdot 0)\end{array}$ & $\begin{array}{l}1.0 \\
1.2 \\
\mathrm{NP} \\
1.3\end{array}$ & $\begin{array}{l}(0 \cdot 3-3 \cdot 1) \\
(0 \cdot 4-3 \cdot 9) \\
(0 \cdot 2-8 \cdot 0)\end{array}$ \\
\hline
\end{tabular}

Explanations as table $4 ; \mathrm{NP}=$ calculations were not possible because numbers were small and several case-control sets had identical values for these variables.
Results for analysis by univariate conditional logistic regression indicated that for the disability control comparison, the odds of neurological disease increased with increasing exposure, although the $95 \%$ CIs all included 1.0: when exposure was expressed by the categories none, less than a year, and a year or more, ORs were $1.0,1.3(95 \%$ CI $0.2-9.6)$, and $2 \cdot 1(95 \% \mathrm{CI} 0 \cdot 5-8 \cdot 7)$ respectively.

For population controls, risk of neurological disease seemed to decrease with increasing exposure duration, as was found with psychiatric disease. For the categories none, less than a year, and one year or more of exposure, ORs were $1.0,1.4(95 \% \mathrm{CI} 0.3-6.1)$, and $0.44(95 \%$ CI $0 \cdot 1-1 \cdot 8)$ respectively.

Effects of potential confounders were examined in analyses similar to those carried out for the group of psychiatric cases and controls. As shown in table 4, univariate analyses suggested that solvent exposure, lead, and alcohol consumption might be related to development of selected neurological diseases. Multivariate analyses did not yield meaningful results because numbers were few.

\section{MULTIPLE SCLEROSIS}

Twenty cases of multiple sclerosis were identified. Mean solvent and lead exposures were substantially greater for cases than those for disability controls and somewhat greater than for population controls (averages of $3 \cdot 2,1 \cdot 1$, and $2 \cdot 3$ years respectively). These trends were confirmed in univariate analyses (table 5).

Univariate conditional logistic regression analyses examining the relation between exposure and multiple sclerosis generally resulted in ORs greater than one for both control groups, regardless of how exposure was expressed (although no increases were statistically significant). A categorical analysis with categories none, less than one year, and one or more years of exposure suggested a doseresponse relation for the disability control comparison, with ORs of $1.0,1.4(95 \% \mathrm{CI}$ $0.3-6.9)$, and $2.9(95 \% \mathrm{CI} 0.6-14.2)$ and $1.0,0.90$ (95\% CI $0.2-3.9)$, and 1.1 (95\% CI $0.3-4.0)$ for disability and population controls respectively.

Univariate regression analyses examining effects of potential confounders determined that those working in skilled trades had a higher risk of multiple sclerosis $(O R=5 \cdot 1$, 95\% CI $0.92-28.4$ in the disability control group comparison; in population controls, the OR was 1.5 , with $95 \%$ CI $0.4-5.85$ ). Although not statistically significant, lead exposure in automobile plants (expressed as less or more than 0.5 years) was also positively associated with risk, with ORs of $8 \cdot 2$ (95\% CI $0 \cdot 7-95 \cdot 1)$ for disability and $1.3(95 \% \mathrm{CI}$ $0.2-7.95$ ) for population controls. Other potential confounders, including prehire exposures to neurotoxicants and alcohol consumption, did not seem to be associated with the outcome.

The number of cases of multiple sclerosis was small making multivariate analysis difficult. One model including two variablesyears of solvent exposure and an indicator 
variable for lead exposure, described earlier suggested that both were related to the outcome in disability controls, with a coefficient of 0.12 for years of solvent exposure (an OR of 1.13 for a one year increase in exposure) and an OR of 4.6 for lead $(p=0.039$ for the model). For population controls, no significant effects were seen: the coefficient was 0.051 for solvent exposure (an OR of 1.05 for a one year increase in exposure) and the OR was 1.15 for lead ( $p=0.60$ for the model).

\section{Discussion}

\section{PSYCHIATRIC DISEASE}

A number of epidemiological studies have suggested that those working in solvent exposed occupations are at increased risk of chronic neuropsychiatric disease. ${ }^{4-14}$ By comparison with the current investigation, solvent exposures tended to be higher or longer in these mostly European studies, as participants were often selected from trade union groups of painters, varnishers, carpet layers, and other occupations with high exposure. Although classification of exposure was often crude (such as exposed $v$ unexposed), ORs for neuropsychiatric disease were generally slightly increased, typically twofold, for exposed groups. Most of those employing quantitative exposure measures found doseresponse relations based on the number of years that study members were exposed to solvents. ${ }^{4} 101113$

In these assembly plants, solvent exposures tended to be short term and low level, although common. It might plausibly be argued that these exposure conditions were not sufficient to cause symptoms or disease resulting in disability. The failure in this study to find positive associations between exposure to solvents and psychiatric disorders might be expected and does not necessarily call into question the positive results found in previous similar studies. Of course, insufficient exposure would normally be expected to result in a lack of association rather than an inverse one.

Additional analyses that attempted to explain the counterintuitive findings by excluding various study participants and using different measures of exposure indicated similar results. Findings also did not seem to be explained by confounding exposures or characteristics. It might be argued that the chosen matching procedure could have resulted in overmatching; however, this should have resulted in bias toward a null rather than an apparent protective effect. Moreover, in an additional analysis carried out with a large subset of the psychiatric cases, rematched to controls only on plant, race, sex, and birth date, results did not change appreciably.

The results may relate to unknown selective factors that are unique to this study population. The healthy worker effect would be expected to operate in a group of workers who develop chronic disability as the years passed, absenteeism would increase and employees might be transferred to positions with less responsibility and perhaps concomitantly, less potential for exposure to solvents. The healthy worker effect would not be expected early in employment, when the workforce is young and purportedly healthy. Differences in solvent exposure were, however, found in the very first job assignments held by study participants, suggesting that cases (and to a lesser extent, disability controls) were selected into low exposure jobs at initial employment. In view of the employment practices of automobile companies, this is puzzling. Discussions with plant personnel directors suggested that when most hourly assembly workers are first employed, very little evaluation takes place. A small percentage are taken into apprenticeship programmes for skilled trades that are highly selective.

There is at least one hypothesis that may be consistent with reported employment practices and yet explain the apparent protective effect of exposure-that is, the requirement that participants had worked for 10 or more years may have led to differential selection of cases and controls based on exposure state. Workers with a predisposition toward psychiatric disorders may have experienced more adverse solvent related effects and tended to leave soon after employment. Most comparable studies also had an inclusion criterion of 10 or more years employment duration, however, and did not yield similar results. In the present study, participants were largely unskilled employees working in a diverse environment with regard to exposure: many jobs and exposure conditions were available in theory, but employees may have had limited opportunity to transfer from undesirable positions and vulnerable persons may have chosen to leave the workforce. By contrast, other studies tended to examine skilled workers who perhaps tended to remain in their jobs because of the training invested and relatively high pay.

\section{NEUROLOGICAL DISEASE}

Although few cases of neurological disease were identified, this group of outcomes seemed to be related to solvent exposure. For the group that excluded multiple sclerosis, a heterogeneous mix of diagnoses, solvent exposure seemed to be positively related to disease in disability control analyses but not in population control comparisons. This group included cases with parkinsonism, chemical neuropathies, and cerebellar atrophy; the last two have been associated with exposure to solvents in case series and cross sectional studies. ${ }^{15}$ Parkinsonism-like syndromes have been found in patients experiencing high exposures to trichloroethylene. ${ }^{16-19}$ In our study, alcohol consumption and occupational exposure to lead also seemed to be important risk factors for neurological disease. Unfortunately, numbers were too few for multivariate analysis to determine the relative effects of these exposures and solvents.

MULTIPLE SCLEROSIS

Solvent exposure was associated with multiple sclerosis in this investigation, despite only 20 
cases being identified. Although none of the case charts contained original laboratory or imaging reports that would confirm the existence of the disorder, based on the symptoms and laboratory findings summarised in physicians' notes, the cases seemed to be appropriately classified..$^{20}$

Investigators have reported illnesses resembling multiple sclerosis in patients overexposed to trichloroethylene and methanol. ${ }^{21} 22$ Others conducting population based casecontrol studies have found that shoe and leather workers exposed to solvents and glues are at higher risk for multiple sclerosis than other occupational groups. ${ }^{23}$ Results from a Swedish case-control study suggested that the risk of multiple sclerosis was increased for males exposed to solvents. ${ }^{24} \mathrm{~A}$ small Finnish study of twins with multiple sclerosis did not find any association with occupational chemical exposures, including solvents, when comparing cases and controls. ${ }^{25}$ Other studies did not examine effects of occupational solvents specifically, but noted an increased risk for multiple sclerosis in hairdressers and workers exposed to zinc. ${ }^{26-27}$

These studies suggest that exposure to solvents may cause a syndrome that mimics multiple sclerosis. Again, in this investigation numbers were few and it was not possible to determine the relative effects of solvents and other exposures, particularly to lead.

This project was funded wholly by joint funds from the United Automobile Workers/General Motors National Joint Committee on Health and Safety.

1 US Department of Health and Human Services. International classification of diseases, 9th revision. Washington, DC: US Government Printing Office, 1991. (DHHS publ No (PHS) 91-1260.)

2 Nelson NA, Robins, TG, Garrison RP, Schuman M, White RF. Historical characterization of exposure to
mixed solvents for an epidemiologic study of automotive mixed solvents for an epidemiologic study of automotive assembly plant wor

3 US Department of Health, Education and Welfare. Occupational Diseases, a guide to their recognition. Washington, DC: US Government Printing Office, 1978. (DHEW (NIOSH) Publ No 77-181.)

4 Axelson $O$, Hane M, Hogstedt C. A case-referent study on neuropsychiatric disorders among workers exposed to solvents. Scand $\mathcal{F}$ Work Environ Health 1976;2:14-20.

5 Brackbill R, Maizlish N, Fischbach T. Risk of neuropsychiatric disability among painters in the United States. Scand $¥$ Work Environ Health 1990;16:182-8.
6 Guberan E, Usel M, Raymond L, Tissot R, Sweetnam PM. Disability, mortality, and incidence of cancer among Geneva painters and electricians: a historical prospective study. Br F Ind Med 1989;46:16-23.

7 Hogstedt C, Axelson O. Long-term health effects of industrial solvents - a critical review of the epidemiologic research. Med Lav 1986;77:11-22.

8 Lindstrom $\mathrm{K}$, Rihimaki $\mathrm{H}$, Hanninen $\mathrm{K}$. Occupational solvent exposure and neuropsychiatric disorders. Scand $\mathcal{F}$ Work Environ Health 1984;10:321-3.

9 Mikkelsen S. A cohort study of disability pension and death among painters with special regard to disabling presenile dementia as an occupational disease. Scand $\mathcal{F}$ presenile dementia as an occup
Soc Med 1980;16(suppl):34-43.

10 Olsen J, Sabroe S. A case-reference study of neuropsychiatric disorders among workers exposed to solvents in the Danish wood and furniture industry. Scand $\mathcal{F}$ Soc Med 1980;16(suppl):44-9.

11 Rasmussen H, Olsen J, Lauritsen J. Risk of encephalopathia among retired solvent-exposed workers. f Occup Med 1985;27:561-6.

12 Riise T, Moen BE. A nested case-control study of disability pension among seamen with special reference to neuropsychiatric disorders and exposure to solvents. Neuroepidemiology 1990;9:88-94.

13 van Vliet C, Swaen GMH, Volovics A, et al. Exposure-outcome relationships between organic solvent exposure and neuropsychiatric disorders: results from a Dutch and neuropsychiatric disorders: results from a D

14 van Vliet C, Swaen G, Volovics, et al. Neuropsychiatric an Vliet C, Swaen G, Volovics, et al. Neuropsychiatric
disorders among solvent-exposed workers. Int Arch Occup Environ Health 1990;62:127-32.

15 Mikkelsen S, Jorgensen M, Browne E, Gyldensted C. Mixed solvent exposure and organic brain damage. Acta Neurol Scand 1988;78(suppl 118):1-97.

16 Defalque RJ. Pharmacology and toxicology of trichloroethylene. A critical review of the world literature. Clin Pharmacol Ther 1961;2:665-88.

17 Feldman RG. Trichloroethylene. In: Vinken PJ, Bruyn GW, eds. Handbook of clinical neurology. Amsterdam: North-Holland Publishing Company, 1979:457-64.

18 Feldman RG, Mayer RM, Taub A. Evidence for peripheral neurotoxic effect of trichloroethylene. Neurology eral neurotoxic effec

19 Huff JE. New evidence on the old problems of trichlorethylene. Industrial Medicine 1971;40:25-33.

20 Poser CM, Pary DW, Scheinberg L, et al. New diagnostic criteria for multiple sclerosis: guidelines for research protocols. Ann Neurol 1983;13:227-31.

21 Henzi $H$. Chronic methanol poisoning with the clinical and pathologic-anatomical features of multiple sclerosis. Med Hypotheses 1984;13:63-75.

22 Noseworthy JH, Rice GP. Trichloroethylene poisoning mimicking multiple sclerosis [letter]. Can $\mathcal{f}$ Neurol $S_{c i}$ 1988;15:87-8.

23 Amaducci L, Arfaoili C, Inzitari D, Marchi M. Multiple sclerosis among shoe and leather workers: an epidemiologic survey in Florence. Acta Neurol Scand 1982; logic survey

24 Flodin U, Soderfeldt B, Noorlind-Brage H, Fredericksson $M$, Axelson $O$. Multiple sclerosis, solvents, and pets. Arch Neurol 1988;45:620-3.

25 Juntunen J, Kinnunen E, Antti-Poika $M$, Koskenvuo $M$. Multiple sclerosis and occupational exposure to chemicals: a co-twin control study of a nationwide series of twins. Br F Ind Med 1989;46:417-9.

26 Souberbielle BE, Martin-Mondiere C, O'Brien ME, Carydakis C, Cesaro P, Degos JD. A case-control epidemiological study of MS in the Paris area with particular reference to past disease history and profession. Acto Neurol Scand 1990;82:303-10.

27 Stein EC, Schiffer RB, Hall WJ, Young N. Multiple sclerosis and the workplace: report of an industry-based cluster. Neurology 1987;37:1672-7. 